\title{
Promoting 21st-century learning through Skype in the Classroom
}

\author{
Luís Filipe Torres Moreira
}

Colégio Casa Mãe - Portugal

\begin{abstract}
In 21 st century technology helps students learn anytime and anywhere. Skype connections bring the world into the 21 st century classroom through social networking and video conferencing. It is possible to engage classrooms and watch students of one class interact with students of other class. This study aims to show the impact of Skype as a tool for effective and significant learning and teaching within a sample of 32 students from middle to secondary school level, that went through skype sessions, during four months, at Natural sciences subject. As researching methods it was implemented a mixed-approach, both quantitative and qualitative, with (i) pre and pos questionnaires, built upon a lickert scale; (ii) semi-structured interviews, pre and pos skype sessions, to randomed selected students and teachers and (iii) an observation scale instrument within each skype session. The first results show that teachers: (i) battle to hold students' short attention spans; (ii) are available for integratting Skype in the classroom and (iii) state that Skype created a whole new world of learning for their students, by bringing them meaningful, real-world experiences. On the other side, students: (i) prefer the Virtual Field Trips, visiting laboratorys, museums, national parks, zoos and (ii) refer that it is important the opportunity to invite scientists from any point of the globe, from Cambridge to Harvard, sharing their expertise and project.
\end{abstract}

Keywords: Classroom; Learning; Skype; Teaching; Technology. 